\title{
An epidemiological study of health and morbidity profile among geriatric population in field practice area of a Medical College in Navi Mumbai
}

\section{Sudarshan Ramaswamy ${ }^{1}$; Sumedha Milind Joshi ${ }^{2}$; Deepa Haritosh Velankar ${ }^{3}$}

${ }^{1}$ NCDC, New Delhi as a WHO Consultant - Health Emergencies NOA, National Public Surveillance Project; ${ }^{2}$ Professor and Head, Department of Community Medicine, D Y Patil School of Medicine, Nerul, Navi Mumbai, Maharashtra; ${ }^{3}$ Professor, Department of Community Medicine, D Y Patil School of Medicine, Nerul, Navi Mumbai, Maharashtra

\begin{tabular}{|c|c|c|c|c|c|c|c|c|}
\hline Abstract & Introduction & Methodology & Results & Conclusion & References & Citation & \multicolumn{2}{|c|}{ Tables / Figures } \\
\hline \multicolumn{9}{|c|}{ ing Author } \\
\hline \multicolumn{8}{|c|}{$\begin{array}{l}\text { Dr. Sumedha M Joshi, Professor and Head, Medical College building, 4th floor, Department of Community } \\
\text { Medicine, DY Patil School of Medicine, Nerul, Navi Mumbai, Maharashtra - } 400706 \\
\text { E Mail ID: sudarshanfine@gmail.com }\end{array}$} & 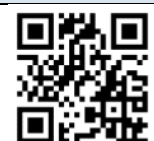 \\
\hline
\end{tabular}

\section{Citation}

Ramaswamy S, Joshi SM, Velankar DH. An epidemiological study of health and morbidity profile among geriatric population in field practice area of a Medical College in Navi Mumbai. Indian J Comm Health. 2021;33(2):266-275. https://doi.org/10.47203/IJCH.2021.v33i02.008

Source of Funding: Nil Conflict of Interest: None declared

\section{Article Cycle}

Received: 22/02/2021; Revision: 18/04/2021; Accepted: 27/05/2021; Published: 30/06/2021

This work is licensed under a Creative Commons Attribution 4.0 International License.

\section{Abstract}

Background: Geriatric population is a very vulnerable group, potentially can suffer many kinds of illnesses "ALL AT ONCE". There is a need for proper planning to tackle the social, financial, psychological and physical problems encountered during old age. In India, proportion of old age population is estimated to rise up to $19 \%$ by $2050{ }^{[1]}$ Objectives: To study the socio demographic and health profile, morbidity prevalence and patterns of various diseases seen in the geriatric age group. To assess the health seeking behavior and the demand for healthcare services in geriatric population. Methodology: This is an epidemiological community based cross-sectional descriptive study on 240 participants aged 60 years and above. Study subjects were interviewed using a questionnaire followed by taking thorough health and morbidity history. General physical examination and Systemic examination was done. Morbidity pattern was analyzed and associations with various determinants were derived. Results: Out of the total 240 subjects, $208(86.67 \%)$ had at least one morbidity and $32(13.33 \%)$ of them dint have any. Association of different parameters with presence or absence of "presenting symptoms, morbidity and multi system morbidity" was analyzed. Variables significantly positive $(P<0.25)$ in univariate analysis were included in multivariate analysis and binary logistic regression model was applied. Lack of sleep, reduced appetite, nutritional deficiency, low literacy, reduced physical activity and history of addictions all have significant association $(P<0.05)$ with either physical symptoms or systemic morbidity. Conclusion: These risk factors worsen the natural aging process and hamper the process of healthy ageing. Measures must be taken to reduce these modifiable risk factors at younger age in order to prevent multifactorial causation of chronic diseases in old age as we're heading towards a demographic shift soon.

\section{Keywords (Max of 06 to be selected)}

Cross-Sectional Studies; Healthy Aging; Chronic Diseases; Multivariate Analysis; Delivery of Health Care; Sleep Deprivation

\section{Introduction}

Geriatric population ( $>60$ years of age) is an extremely vulnerable group, having the potential to suffer multiple communicable and non-communicable illnesses. Geriatric population in India during the year 2010 was around 8\% and the proportion is estimated to rise to $19 \%$ by 2050 . Geriatric population in 2016 was $9 \%$, from which it was noted that $40 \%$ were below poverty line, $69 \%$ lived in rural areas, $73 \%$ were illiterates (hence, can only be engaged for unskilled work), and $55 \%$ of geriatric women were widows.(1) Proper planning is necessary to tackle the social, financial, psychological and physical problems encountered during old age. A document published by Population Foundation of India predicts that the average Life expectancy at birth in India shall be above 75 by 2040 and over 79 by 2060.(2) It also predicts that the percentage of population above 65 years consistently increases throughout this century (from 4.8\% during 2001 to $15.1 \%$ by 2060 ). Lack of age specific interventional measures, inadequate infrastructural facilities, coupled with ever increasing risk of age-related diseases and the 
trend of rising proportion of elderly population, pose a serious challenge to the healthcare delivery system and utilization. Ageing leads to a gradual decrease in physical and mental capacity, a growing risk of disease, and ultimately, death. But these changes are neither linear nor consistent, and they are only loosely associated with a person's age in years. Beyond biological changes, ageing is also associated with other life transitions such as retirement, relocation to more appropriate housing, and the death of friends and partners.(3) Ageing, although is a natural phenomenon affecting homeostasis negatively over time, becomes worrisome when "biological age" is greater than the "chronological age". In order to study the effect of ageing on health, risk factors associated with abnormal ageing and to discuss the way forward, following study was conducted.

\section{Aims \& Objectives}

1. To study the socio demographic, health and morbidity profile, the prevalence and patterns of various diseases seen in the geriatric age group.

2. To assess the health seeking behaviour and the demand for healthcare services in geriatric population.

\section{Material \& Methods}

Study design and setting: It is a Community based crosssectional descriptive study conducted in a field practice area of the Department of Community Medicine of a tertiary hospital and College in Navi Mumbai. The study was carried out for a period of 24 months from July 2017 to June 2019. A prior Ethical Committee permission was taken from the parent institution for the study.

Determination of sample size: At the beginning of the study, a pilot study was conducted on 25 subjects using an initial questionnaire. This is an original questionnaire created exclusively for this study based on the data requirements. The questionnaire included sociodemographic details of the participants, history of any presenting symptoms, morbidity history (pre-existing diseases), personal history and questions on healthseeking behaviour. Additionally, details of Activities of Daily Living were taken, and Geriatric Depression scale was used for assessing the psychological status. Following minor changes to the initial questionnaire from pilot study, a final questionnaire was designed and validated for data collection of the actual study. Validation was done by taking the inputs of various faculty of the Department of Community Medicine, considering the pilot study as a reference. As per the pilot study, 21(84\%) subjects had at least one morbidity (diagnosed disease / ill-health - Symptomatic + asymptomatic). Considering the average morbidity prevalence from our pilot study and few similar previous studies Kamlesh Joshi et al(4), Krishnamachari Srinivasan et al(5), Bhatia et al(6), Shahul Hameed et al(7), prevalence of morbidity to calculate the sample size of current study was estimated at
$87.5 \%(88 \%)$. With an allowable error (relative) of $5 \%$, the sample size was calculated using the formula: $4 \mathrm{pq} / 12=218$ subjects. Considering $10 \%$ data attrition, overall sample size was estimated to be $218+22=240$.

Collection of Data: The field practice area of UPHC attached to the parent Medical college is found to be having a population of 45,183 and the total households being 15,338. All the areas under the urban field practice area were listed alphabetically and 2 areas were selected randomly using lottery method. The areas thus selected randomly were found to be Sector 3 (including 3A) and Shivaji Nagar. The selected field area consists of 3210 households and a total population of 9,243. By referring to the official records from the Urban Health Centre catering the study area, the geriatric population in the area under study was found to be 795 . For collecting the data, first house was selected randomly by standing at the entrance of the area based on the last digit present on a Rs10 note in the pocket of the field investigator on the first day of data collection. Subsequently, data was collected by systematic random sampling method and every 3rd house was surveyed. If the third house did not have a geriatric person, then the next house was surveyed and so on until sample size of 240 was reached. Based on a pretested (pilot study inputs) and pre-validated (among the staff members of the department and the institutional review board) questionnaire, a house to house survey was conducted. Survey interview was conducted in Hindi/local language whichever was more convenient for the subject. Personal information, clinical and socio-demographic history was taken, their geriatric depression rating was estimated using Geriatric Depression Scale,(8) General Physical Examination was done, and all the findings were documented. Symptomatology and morbidity patterns of the participants were assessed. Information regarding Health-seeking behaviours in the community among the geriatric population was gathered. Health education and advice was given on the healthcare policies for elderly and services available for them. Subjects with positive clinical findings were referred to the attached tertiary hospital for investigations and further assessment.

Statistical analysis: Data collected was entered in Microsoft Excel Version 2013 and analysed using IBM SPSS Statistics Software Version 22. To find the various parameters/determinants influencing the "presence or absence of presenting symptoms", "presence or absence of morbidity" and "presence or absence of multisystemic involvement" among the geriatric population, Chi square test was applied for univariate analysis and binary logistic regression model was applied for multivariate analysis. The independent variables for univariate analysis were selected on prior basis based on review of literature that were regarded as having most chances of influencing the dependent variables. Variables which were not found significantly associated were excluded. Subsequently, independent variables having $P$ value $<0.25$ were included 
in regression model for multivariate analysis. Forward Likelihood Ratio was used to find the significant predictors of the dependent variables. The criteria for entering and removing the independent variables from the forward stepwise model was $\mathrm{P}<0.05$ and $\mathrm{P}>0.10$ respectively. In the final model all possible interactions having biological plausibility were checked.

\section{Results}

Overall mean age of the study population was 65.7 years with a Standard Deviation of 4.2 years. Out of 240 subjects, $119(49.6 \%)$ were males and $121(50.4 \%)$ were females, 223(92.9\%) subjects were married and $17(7.1 \%)$ were widowed. According to modified Kuppuswamy socioeconomic scale, $31(12.9 \%)$ subjects belonged to class II, 88(36.7\%) belonged to class III and $121(50.4 \%)$ belonged to class IV.(9) The overall literacy rate was $42.9 \%$.Out of 240 subjects, $190(79.17 \%)$ presented with one or more symptoms (presenting complaints). Only the single most prominent symptom per subject was included in the study. Distribution of common symptoms found during the study is shown in (Figure 1). Most common organ-system involvement observed as per symptomatology was Musculoskeletal(85, 44.74\%), followed by Ophthalmologic(31, 16.32\%) and Respiratory(18, 9.47\%).

Our study found $208(86.67 \%)$ subjects with at least one morbidity (previously diagnosed disease / ill-health). Distribution of morbidity (disease) pattern found is shown in (Table 1). Most common organ-system involvement observed as per morbidity was Cardiovascular (71, $29.58 \%)$, followed by Endocrine (68, 28.33\%) and Musculoskeletal(28, 14.58\%). Among 240 subjects, $32(13 \%)$ had no systemic involvement, 99(41\%) had single system morbidity and 109(46\%) had multisystem morbidity. Out of 208 subjects who had morbidity, $179(86 \%)$ claimed taking regular treatment and 29(14\%) did not. Most common reason reported for not taking treatment was financial constraint. This is further justified by the responses received to the questionnaire on health seeking behavior (healthcare utilization and illness response) as shown in the (Table 2). 84(35\%) of the study population reported the presence of deficiency in average per capita expenses required and that is catered for personal healthcare. Yet 153(63.75\%) reported utilizing private pharmacies for procuring medicines and $211(87.9 \%)$ had no health insurance coverage.

In our study, $18(7.5 \%)$ subjects were found to have reduced appetite, $188(78.3 \%)$ were doing insufficient physical activity, 32(13\%) had insufficient sleep, 28(11.7\%) had deficient calorie intake, $30(12.5 \%)$ had deficient protein intake. $(10,11,12,13)$ Most common reasons for lack of sleep were family stress, financial stress and mental stress. Among 240 subjects, 9(3.75\%) were dependent on others for activities of daily living and $60(25 \%)$ were dependent for instrumental activities of daily living. $(14,15)$ The study showed that $23(10 \%)$ subjects had depression according to the Geriatric Depression Scale.(8) Among them, 18(78.3\%) had mild depression, 3(13\%) had moderate level of depression and $2(8.7 \%)$ had severe form of depression. (Table 3) represents the distribution of systemic morbidity according to various age groups and BMI. Although not statistically significant, the chances of having morbidity increases with advancing age. But age group is not a significant predictor of morbidity status after 60 years of age in the current study. We also notice that the underweight and obese subjects have more chances of having morbidity as compared to normal or overweight subjects, although not statistically significant. No significant association between Socio economic status and morbidity pattern was seen in the study.

(Table 4) shows association of different parameters with presence or absence of "presenting symptoms". The full model containing all predictors after multivariate analysis was statistically significant with Chi square value of 50.129 $(P<0.000)$. Hosmer - Lameshow goodness of fit test was applied which showed a significance of 1.000 ( $P$ value) and Chi square value of $<0.000$. Nagelkerke R Square value was 0.275 implying that $27.5 \%$ of the association with presenting symptoms could be explained by this model. The overall predictability of the model is $80.4 \%$ ie., the model predicts $80.4 \%$ of the overall cases correctly. The model predicts $92 \%$ of the cases who are having presenting symptoms correctly and $48.2 \%$ of the cases who are not having physical symptoms. Finally, following independent variables were found to be significant:

I. Physical activity: Odds of having presenting symptom is 10 (9.8) times ( $\mathrm{Cl}: 4.789-20.054, \mathrm{P}<0.000)$ higher among people who do not perform the recommended physical activity as compared to people who do. In our study, inadequate physical activity was considered as less than 150 minutes (2 hours and 30 minutes) a week of moderate-intensity, or 75 minutes ( 1 hour and 15 minutes) a week of vigorous-intensity aerobic physical activity, or an equivalent combination of moderate- and vigorousintensity aerobic activity.(10)

II. Sleep: Lack of sleep significantly increases the odds of having presenting symptom by $5.5(1 / 0.182)$ times (Cl: $0.048-0.692, \mathrm{P}=0.012$ ) as compared to people having regular and sufficient sleep. In our study, less than 7 hours sleep a day was considered as inadequate sleep.(11)

(Table 5) shows association of different parameters with presence or absence of "morbidity". The full model containing all predictors after multivariate analysis was statistically significant with Chi square value of 40.387 ( $P$ $<0.000$ ). Hosmer - Lameshow goodness of fit test was applied which showed a significance of 1.000 ( $P$ value) and Chi square value of $<0.000$. Nagelkerke $R$ Square value was 0.232 implying that $23.2 \%$ of the association with 
presence of morbidity could be explained by this model. The overall predictability of the model is $86.7 \%$ ie., the model predicts $80.4 \%$ of the overall cases correctly. The model predicts $100 \%$ of the cases who are having morbidity correctly and $0 \%$ of the cases who are not having any morbidity. So, this model is a good predictor of presence of morbidity but fails to pick up people without morbidity. Finally, following independent variables were found to be significant:

1. Physical activity: Odds of having morbidity is 8 (7.7) times ( $\mathrm{Cl}$ : 3.401 - 17.275, $\mathrm{P}<0.000)$ higher among people who do not perform the recommended physical activity as compared to people who do.

(Table 6) shows association of different parameters with presence or absence of "multi system morbidity". The full model containing all predictors after multivariate analysis was statistically significant with Chi square value of 28.698 $(P<0.000)$. Hosmer - Lameshow goodness of fit test was applied which showed a significance of 0.909 ( $P$ value) and Chi square value of $<0.013$. Nagelkerke R Square value was 0.156 implying that $15.6 \%$ of the association with presenting symptoms could be explained by this model. The overall predictability of the model is $65.8 \%$ ie., the model predicts $65.8 \%$ of the overall cases correctly. The model predicts $93.1 \%$ of the cases who are having multi system morbidity correctly and $33 \%$ of the cases who are not having multisystem morbidity. Finally, following independent variables were found to be significant:

I. Depression: Odds of having multisystem morbidity is 6.3 times $(\mathrm{Cl}: 2.031-19.531, \mathrm{P}<0.000)$ higher among people who have depression as compared to people who do not. It can also be the other way around, since multisystem morbidity can also be a causal factor for having depression. Thus, depression and multisystem morbidity should be considered as co-existent conditions since a shade of grey area exists between quantifying the cause-effect relationship in this case.

II. Addictions / Habits: Among people who do not have addictions, odds of having multisystem morbidity decreases by 6 (1/0.166) times $(\mathrm{Cl}: 0.059-0.462, \mathrm{P}=$ 0.001 ) as compared to people have. In our study, Addictions / habits were considered (operational definition for this study only) positive for people who reported regular consumption of any one of the following - 1) Alcohol, 2) Smoking, 3) Consumption of Tobacco in any other form, 4) Other intoxicants or drugs for at least a period of 5 years or more.

\section{Discussion}

Among all the important indicators of geriatric health, the current study focuses mostly on the following four subgroups:

Physical Symptoms: Our study shows that prevalence of physical symptoms is $80 \%$ among the study group and the distribution of systemic complaints had similar findings to a study Ajay Kumar Pandita et al.(15) It can be submitted from the study that lower prevalence of physical symptoms would actually constitute healthy aging in a community. Presence or absence of physical symptoms to chronic diseases is a good indicator to assess the general health of a community and targeted interventions on a priority basis (Eg: Joint pain/stiffness, low vision, breathlessness - three most common symptoms from this study) should be undertaken to prevent / reduce their prevalence in the geriatric subpopulation. Eg: Regular calcium supplementation, spreading awareness about calcium deficiency, enough protein intake and joint mobility exercises in older age groups could significantly reduce the joint stiffness/pain.

Morbidity: Morbidity pattern in comparable previous studies show a varied spectrum of results. The study Jai Prakash Singh et al(16) and Radhakrishnan et al(17) show prevalence of diabetes was $17.75 \%$ and $36 \%$ respectively. Prevalence of hypertension was $30.7 \%$ in Thakur RP et al(18), 29.3\% in Shraddha et al(19), 25.9\% in Purty Anil Jacob et al.(20) Hypertension and type 2 Diabetes are components of "Metabolic syndrome". Both hypertension and diabetes share common risk factors, contributing to worsening of each other's symptoms and shorten overall lifespan. In our study the prevalence of osteo arthritis was found to be on the lower side as compared to previous studies Chandra Prakash Pal et al(21), Shraddha et al(19) and Rahul Prakash et al(22), since only previously diagnosed cases of morbidities were considered positive and everyone with symptoms were not termed so. Although $28.3 \%$ presented with joint pain only $12 \%$ were previously diagnosed with Osteo arthritis. Since most of the chronic non communicable diseases exhibit iceberg phenomenon, identifying them early by screening techniques and quick interventional measures would ensure healthy aging.

Dermatological infections are one of the common conditions which are prevalent in the community and the prevalence found in our study is in accordance with a systematic review by Elisabeth Hahnel et al.(23) Tenia is one of the most common skin infections. Due to high cost of treatment, they are usually neglected by lower socioeconomic group. Improper treatment without radical cure causes relapse and further spread of infection within the individual and to contacts. Prevalence of respiratory illnesses found in our study is comparable to the results of few previous studies Purty Anil Jacob et al(20), A Lena et al(24), Deepak Sharma et al(25). Smoking, indoor and outdoor air pollution, genetic factors, low immunity, under-nutrition are risk factors for developing respiratory diseases. Health education, poverty reduction and increasing practical awareness of air pollution would be the corner stone in achieving reduction of their prevalence. Healthy diet and lifestyle in young age would prevent or delay such consequences.

Multisystem Morbidity: "The problem with aging is not that it's one damn thing after another: it's every damn 
thing, all at once, all the time." - John Scalzi. Presence of common risk factors and multifactorial causation of diseases results in overlapping spectrum of morbidity during old age. In our study $13 \%$ subjects had no systemic involvement, $41 \%$ had single system involvement and $46 \%$ had multisystem morbidity similar the studies by Banjare $\mathrm{P}$ et al(26), Hien $\mathrm{H}$ et al(27), Akriti Gupta et al $(27,28)$ reported prevalence of multisystem morbidity as 58\%, $65 \%$ and $65.9 \%$ respectively. These results indicate that every second person in geriatric population show multi system involvement. A study in China by Wang et al observed the prevalence to be as high as 90\%.(29) Apart from increasing the burden on healthcare, high prevalence of multisystem morbidity is always a threat to the society in terms of productivity.

Our study showed that $7.5 \%$ of subjects had reduced appetite, $78.3 \%$ were doing insufficient physical activity, $13 \%$ had reduced sleep (insomnia), $11.7 \%$ had calorie intake deficiency, $12.5 \%$ had protein intake deficiency and $10 \%$ had depression. A comparable study Gambhir et al(30) reported $32 \%$ prevalence of insomnia among elderly population. This actually suggests that the actual prevalence could actually be higher since our study only considered people getting <7hours a day sleep regularly as insomnia as compared to the above study which used a more detailed questionnaire on insomnia and categorized into early, mid, late and hyper - insomnia which also reports significant association between depression and insomnia.

Heath seeking behaviour: For physicians, treatment of a patent doesn't end after writing a prescription but a need to ensure adherence to the medications for maximizing therapeutic benefits. In our study, among 208 subjects who had at least one morbidity, at least $14 \%$ were either not taking treatment or not adhering to the prescribed medications. Similar findings were observed in the study Zachary A.Marcum et al which reported non-adherence as per the MMAS-4 and CRN-2 scale were $40.7 \%$ and $7.7 \%$ respectively, with an overlap of 3.7\%.(31) Our study included only single question which still reported $14 \%$ non-adherence. Most common reason for not taking treatment was financial constraint. Study results on healthcare utilization indicate that there is a great need for increased community participation in tackling the issue of geriatric healthcare. Financial support from the state alone doesn't solve all the problems but constant and persistent strategies of risk communication and community engagement coupled with building social support system at the individual and the community level shall be the crux of planning major programs addressing the issue. Although there is an availability of generic drug supply from the government, there is reluctance in getting the medications. Factors causing the problem at each step must be addressed individually with special attention. Few problems identified in this study are financial constraint, lack of intent and awareness about healthy ageing, lack of trust in generic medicines, proximity, reluctance in government supplies at the bottom level, infiltration of faith healers and quacks into communities. Similarly, all the aspects of healthcare utilization and health seeking behaviour are supposed to be assessed and then prompt measures must be taken to improve the "Social Capital" of the community. In this study, $88 \%$ of the population did not have any form of health insurance. Recently, PMJAY (Pradhan Mantri Jan Arogya Yojana)/Ayushman Bharat Yojana was introduced as a part of government's initiative to provide Universal Health Coverage (UHC - WHO theme 2018 \& 19). Steps must be taken to address the shortfalls of street level bureaucracy and make sure that such schemes reach the unreached population as soon as possible.

\section{Conclusion}

Various parameters which were hypothesized to be associated with "Presence or absence of presenting symptoms and/or morbidity (single/multisystem)" were assessed in our study. It was found that lack of sleep, reduced appetite, nutritional deficiency, low literacy, reduced physical activity and history of addictions all were found to have significant association independently with either physical symptoms or systemic morbidity [Tables 4, $5 \& 6]$. These risk factors hamper the natural / healthy aging process. As compared to youth or young adults, people of geriatric age group are extremely vulnerable to potentially suffer multiple problems at the same time. Management of diseases too pose a greater challenge in such patients since they are more prone to undernourishment and deficient immune status. Addressing these parameters to reduce such modifiable risk factors at younger age helps in preventing unnecessary burden on healthcare system, helps in enjoying healthy and longer life at an individual level, reduces burden at the family level, ensures a healthy elderly population at the community level, increases production and stability in economy at the state/national level and intensifies the march of humankind towards sustainable development at the global level. Community participation and engagement indicated by improvement in components of health seeking behavior is also a very essential for healthy aging of a community. As a measure of preparedness and also learning from the example set by the COVID-19 pandemic (Case Fatality Rate is higher among elderly) (32), working towards the concept of healthy ageing of the population can save millions of lives in future. Recent study Vollset S E, Goren E et al(33) indicate that India is rapidly moving towards population peak, which is followed by decline, suggesting that proportion of dependent population (geriatric group) shall grow faster. Current Demographic dividend of India can turn into a demographic liability in future. It is essential to conduct largescale multicentric studies on similar lines to establish association between the risk factors and 
INDIAN JOURNAL OF COMMUNITY HEALTH / VOL 33 / ISSUE NO 02 / APR- JUN 2021 geriatric morbidity and subsequently formulate a national action plan to address the issue on priority basis.

\section{Recommendation}

Study results emphasize the importance of various preventive measures that can be taken to have a healthier elderly population in the community, such as:

1. Health education, legislative awareness, financial risk protection (Health Insurance and Social Security) of elderly. - Primordial prevention

2. Prompt measures to improve the Social Capital of the community such as "Time banking" (34) and amplify Community participation.- Primary prevention

3. Rapid strengthening of existing healthcare infrastructure, establishment of special geriatric care centers, planning and implementation of related health programs. - Secondary prevention

4. Involvement of NGOs and other private players in taking care of the elderly population, setting up old age homes, philanthropic institutions, and establishment of rehabilitation centers etc. - Tertiary prevention.

Similar to savings during the middle-age foreseeing the post- retirement requirements, prompt preventive interventions are recommended without further ado against the future public health concern.

\section{Limitation of the study}

1. The study cannot be generalized at national or international level since the socio demographic and economic factors of many communities are different.

2. Since the study was not a longitudinal study, daily assessment was not undertaken.

\section{Relevance of the study}

Our study adds to the existing database on prevalence of morbidity among geriatric population in India, additionally quantifies the probable associated risk factors to be addressed on priority basis. Currently, the proportion of geriatric population is lower than the overall average of the World. However, as the present-day middle-aged population reaches the geriatric age group, the scenario is expected to be very different. High prevalence of geriatric morbidity, lack of health insurance and inadequate Psychosocial support systems in the community needs immediate attention.

\section{Authors Contribution}

SR the principle investigator of the study. SMJ \& DHV have guided SR in designing the research question, performing the analysis and writing the research paper.

\section{References}

1. India's Aging Population. Population reference bureau. Available from: http://www.prb.org/Publications/Reports/2012/india-olderpopulation.aspx [Accessed on 20/06/21]

2. The Future POPULATION of India, A Long-range Demographic View. Available from: http://www.indiaenvironmentportal.org.in/files/futurepopulation ofindia.pdf [Accessed on 20/06/21]
[An epidemiological study...] | Ramaswamy S et al

3. WHO Newsroom. Ageing and health. Available from: https://www.who.int/news-room/fact-sheets/detail/ageing-andhealth [Accessed on 20/06/21]

4. Joshi K, Kumar R, Avasthi A. Morbidity profile and its relationship with disability and psychological distress among elderly people in Northern India. International Journal of Epidemiology. 2003 Dec 1;32(6):978-87.

5. Srinivasan K, Vaz M, Thomas T. Prevalence of health related disability among community dwelling urban elderly from middle socioeconomic strata in Bangaluru, India. Indian Journal of Medical Research. 2010 Apr 1;131(4).

6. Bhatia SP, Swami HM, Thakur JS, Bhatia V. A study of health problems and loneliness among the elderly in Chandigarh. Indian Journal of Community Medicine. 2007 Oct 1;32(4):255.

7. Hameed S, Kumar N, Naik PM, Sachidananda K, Prasanna KS. Morbidity pattern among the elderly population in a rural area of Dakshina Kannada, Karnataka-a cross sectional study. National Journal of Community Medicine. 2015 Apr;6(2):222-5.

8. Yesavage JA. Geriatric depression scale. Psychopharmacol Bull. 1988 Jan 1;24(4):709-11.

9. Saleem SM. Modified Kuppuswamy socioeconomic scale updated for the year 2019. Indian Journal of Forensic and Community Medicine. 2019 Jan;6(1):1-3.

10. Physical Activity Guidelines Advisory Committee. Physical Activity Guidelines for Americans. Washington (DC): US Department of Health and Human Services; 2008. p. 15-34.

11. How Much Sleep Do I Need? Available from: https://r.search.yahoo.com/_ylt=Awr9lk08.VFfLNYAJlhXNyoA;_ylu $=Y 29$ sbwNncTEEcG9zAzEEdnRpZAMEc2VjA3Nj/RV=2/RE=1599236 541/RO=10/RU=https\%3a\%2f\%2fwww.webmd.com\%2fsleepdisorders\%2fsleeprequirements\%23\%3a \%3atext\%3dMost\%2520adults\%2520need \%25207\%2520to\%25209\%2520hours\%252C\%2520although\%2cne ed\%2520several\%2520more\%2520hours\%2520of\%2520sleep\%25 20than\%2520usual./RK=2/RS=tKSs1rk3E.fliPnzInchDVUtXPU[Accessed on 20/06/21]

12. WHO. Healthy diet. Available from: https://www.who.int/newsroom/fact-sheets/detail/healthy-diet [Accessed 26 June 2021]

13. Parker MG, Thorslund $M$. Health trends in the elderly population:getting better and getting worse. Gerontologist. 2007;47(2):150-8.

14. Lawton MP. Assessing the competence of older people. In: Kent D, Kastenbaum R, editors. Research, planning and action for the elderly. Sherwood: Behavioral Publications; 1972.

15. Pandita AK, Roy D, Saxena V. A study on morbidity pattern among geriatric population of an urban slum, Dehradun, India. Indian Journal of Community Health. 2017;29(4).

16. Singh J, Saoji AV, Kasturwar NB, Pitale SP, Deoke AR, Nayse JG. Epidemiological study of diabetes amongst geriatric population in an urban slum, Nagpur. National Journal of Community Medicine. 2011;2(2):204-8.

17. Radhakrishnan, Shankar; Balamurugan, Sangeetha. Prevalence of diabetes and hypertension among geriatric population in a rural community of Tamil Nadu. Indian Journal of Medical Sciences. 2013, 67( 5/6): 130-136.

18. RP Thakur, A Banerjee, and VB Nikumb. Health Problems Among the Elderly: A Cross-Sectional Study. Ann Med Health Sci Res. 2013; 3(1): 19-25. doi: 10.4103/2141-9248.109466

19. Shraddha K, Prashantha B, Prakash B. Study on morbidity pattern among elderly in urban population of Mysore, Karnataka, India. International Journal of Medicine and Biomedical Research. 2012;1(3):215-223.

20. Purty Anil Jacob, BAZROY Joy, Kar Malini, Vasudevan Kavita,VELIATH Anita, PANDA Purushottam. Morbidity Pattern among the Elderly Population in a rural area of Tamil Nadu, India. Turkish Journal of Medical Sciences. 2005;36(1)

21. Chandra Prakash Pal, Pulkesh Singh, Sanjay Chaturvedi, Kaushal Kumar Pruthi, and Ashok Vij. Epidemiology of knee osteoarthritis in India and related factors. Indian J Orthop. 2016 Sep; 50(5): 518522. doi: 10.4103/0019-5413.189608 
INDIAN JOURNAL OF COMMUNITY HEALTH / VOL 33 / ISSUE NO 02 / APR- JUN 2021

22. Prakash R, Choudhary SK, Singh US. A study of morbidity pattern among geriatric population in an urban area of Udaipur, Rajasthan. Indian J Community Med. 2004 Jan 1;29(1):35-40.

23. Hahnel E, Lichterfeld A, Blume-Peytavi U, Kottner J. The epidemiology of skin conditions in the aged: a systematic review. Journal of tissue viability. 2017 Feb 1;26(1):20-8.

24. Lena A, Ashok K, Padma M, Kamath V, Kamath A. Health and social problems of the elderly: A cross-sectional study in Udupi Taluk, Karnataka. Indian journal of community medicine: official publication of Indian Association of Preventive \& Social Medicine. 2009 Apr;34(2):131.

25. Deepak Sharma, Salig Ram Mazta, and Anupam Parashar.Morbidity Pattern and Health-seeking Behavior of Aged Population residing in Shimla Hills of North India: A Cross-Sectional Study. J Family Med Prim Care. 2013 Apr-Jun; 2(2): 188-193

26. Banjare $P$, Pradhan J. Socio-economic inequalities in the prevalence of multi-morbidity among the rural elderly in Bargarh District of Odisha (India). PLoS ONE 2014;9(6):e97832.

27. Hien $H$, Berthe $A$, Drabo $M$, et al. Prevalence and patterns of multimorbidity among the elderly in Burkina Faso: cross-sectional study. Trop Med Int Health 2014;19(11):1328-1333.

28. Akriti Gupta, Sangeeta Girdhar, Anurag Chaudhary, Jasneet Singh Chawla, Pushapindra Kaushal. Patterns of multimorbidity among elderly in an urban area of North India. J. Evolution Med. Dent. 2016;5(19)
[An epidemiological study...] | Ramaswamy $S$ et al

29. Wang R, Yan Z, Liang $Y$, Tan EC, Cai C, Jiang H, Song A, Qiu C. Prevalence and patterns of chronic disease pairs and multimorbidity among older chinese adults living in a rural area. PLOS ONE 2015;10(9):e0138521.

30. Gambhir IS, Chakrabarti SS, Sharma AR, Saran DP. Insomnia in the elderly-a hospital-based study from North India. Journal of Clinical Gerontology and Geriatrics. 2014 Dec 1;5(4):117-21.

31. Marcum ZA, Zheng $Y$, Perera $S$, Strotmeyer $E$, Newman AB, Simonsick EM, Shorr RI, Bauer DC, Donohue JM, Hanlon JT, Study HA. Prevalence and correlates of self-reported medication nonadherence among older adults with coronary heart disease, diabetes mellitus, and/or hypertension. Research in Social and Administrative Pharmacy. 2013 Nov 1;9(6):817-27.

32. Kang SJ, Jung SI. Age-related morbidity and mortality among patients with COVID-19. Infection \& chemotherapy. 2020 Jun;52(2):154

33. Vollset SE, Goren E, Yuan CW, Cao J, Smith AE, Hsiao T, Bisignano C, Azhar GS, Castro E, Chalek J, Dolgert AJ. Fertility, mortality, migration, and population scenarios for 195 countries and territories from 2017 to 2100: a forecasting analysis for the Global Burden of Disease Study. Lancet 2020; 396: 1285-306.

34. Lasker J, Collom E, Bealer T, Niclaus E, Young Keefe J, Kratzer Z, Baldasari L, Kramer E, Mandeville R, Schulman J, Suchow D. Time banking and health: the role of a community currency organization in enhancing well-being. Health promotion practice. 2011 Jan;12(1):102-15.

\section{Tables}

\section{TABLE 1 DISTRIBUTION OF MORBIDITY PATTERN}

\begin{tabular}{|c|c|c|}
\hline Disease & Frequency & Percentage of people affected (Out of 240) \\
\hline Alzheimer's disease & 1 & $0.42 \%$ \\
\hline Asthma & 10 & $4.17 \%$ \\
\hline $\mathrm{BPH}$ & 6 & $2.5 \%$ \\
\hline Cataract b/l & 7 & $2.92 \%$ \\
\hline Chronic Bronchitis, COPD, ILD & 9 & $3.75 \%$ \\
\hline Chronic constipation, Anal fissure, Hemorrhoids & 6 & $2.5 \%$ \\
\hline Diabetes & 67 & $27.92 \%$ \\
\hline Chronic Gastritis & 2 & $0.83 \%$ \\
\hline Hypertension & 58 & $24.17 \%$ \\
\hline $\mathrm{H} / \mathrm{O} \mathrm{MI}$ & 4 & $1.67 \%$ \\
\hline H/o stroke & 4 & $1.67 \%$ \\
\hline H/o major surgeries/trauma & 7 & $2.92 \%$ \\
\hline Gall stones & 1 & $0.42 \%$ \\
\hline H/o TB & 3 & $1.25 \%$ \\
\hline Chronic Heart disease & 5 & $2.08 \%$ \\
\hline Radiculopathy, PIVD & 12 & $5 \%$ \\
\hline Varicose veins & 4 & $1.67 \%$ \\
\hline Tenia & 12 & $5 \%$ \\
\hline Osteo Arthritis & 28 & $11.67 \%$ \\
\hline Schizophrenia & 2 & $0.83 \%$ \\
\hline Dementia & 1 & $0.42 \%$ \\
\hline Depression & 1 & $0.42 \%$ \\
\hline Hypothyroidism & 1 & $0.42 \%$ \\
\hline Parkinsonism & 2 & $0.83 \%$ \\
\hline Urinary incontinence & 1 & $0.42 \%$ \\
\hline
\end{tabular}




\section{TABLE 2 HEALTH SEEKING BEHAVIOR}

\begin{tabular}{|lccc|}
\hline \multicolumn{1}{l}{$\begin{array}{l}\text { Questions } \\
\text { Have you ever been hospitalized for any problems after }\end{array}$} & Options & Frequency & Percentage \\
years? & No & 54 & $22.5 \%$ \\
\hline What type of healthcare facility do you visit when you fall & Yes & 154 & $64.2 \%$ \\
\hline ill? & Private & 86 & $35.8 \%$ \\
\hline What system of medicine do you use? & Allopathy & 204 & $85 \%$ \\
\hline & Ayurveda & 16 & $6.7 \%$ \\
\hline Where do you get medicines from? & Homeopathy & 20 & $8.3 \%$ \\
\hline Whose support do you get when you are hospitalized? & Government & 87 & $36.25 \%$ \\
\hline & Private & 153 & $63.75 \%$ \\
\hline What kind of support do you get from them? & Family & 107 & $44.6 \%$ \\
\hline Financial/hospital support? & Friends & 25 & $10.4 \%$ \\
\hline & Nil & 82 & $34.2 \%$ \\
\hline Is there any difference between the average per capita & Son & 26 & $10.8 \%$ \\
\hline expenses required and that is catered for your healthcare? & Both & 95 & $39.6 \%$ \\
\hline Do you feel that you don't get enough healthcare services? & Financial & 25 & $10.4 \%$ \\
\hline & Hospital support & 38 & $15.8 \%$ \\
\hline If yes, what kind of support do you feel lacking? & Nil & 82 & $34.2 \%$ \\
\hline & Deficiency & 84 & $35 \%$ \\
\hline & No & 156 & $65 \%$ \\
\hline Do you have health insurance? & No & 97 & $40.4 \%$ \\
\hline & Yes & 143 & $59.6 \%$ \\
\hline
\end{tabular}

\begin{tabular}{|c|c|c|c|c|c|}
\hline & & No Morbidity & $\begin{array}{l}\text { Single system } \\
\text { Morbidity }\end{array}$ & Multi system Morbidity & $\begin{array}{l}\text { P value Fisher's } \\
\text { Exact test. }\end{array}$ \\
\hline & & No. (\%) & No. (\%) & No. (\%) & \\
\hline \multirow{6}{*}{ Age Group } & 60 - 64 years & $13(12.5)$ & $44(42.3)$ & $47(45.2)$ & \multirow{6}{*}{0.1752} \\
\hline & $65-69$ years & $13(15.5)$ & $39(46.4)$ & $32(38.1)$ & \\
\hline & $70-74$ years & $6(13.3)$ & $12(26.7)$ & $27(60)$ & \\
\hline & $75-79$ years & $0(0)$ & $4(80)$ & $1(20)$ & \\
\hline & $80-85$ years & $0(0)$ & $0(0)$ & $2(100)$ & \\
\hline & Total & $32(13.3)$ & $99(41.2)$ & $109(45.4)$ & \\
\hline \multirow{5}{*}{$\begin{array}{l}\text { BMI } \\
\text { Group }\end{array}$} & Under Weight $(<18.5)$ & 0 & $2(33.3)$ & $4(66.7)$ & \multirow[t]{5}{*}{0.5817} \\
\hline & Normal (18.5 - 24.99) & $17(12.1)$ & $58(41.1)$ & $66(46.8)$ & \\
\hline & Over Weight (25 - 29.99) & $15(17)$ & $35(39.8)$ & $38(43.2)$ & \\
\hline & Obesity 1 ( $\geq 30$ ) & $0(0)$ & $4(80)$ & $1(20)$ & \\
\hline & Total & 32 (13.3) & 99 (41.3) & $109(45.4)$ & \\
\hline
\end{tabular}


TABLE 4 ASSOCIATION OF DIFFERENT PARAMETERS WITH PRESENCE OR ABSENCE OF “PRESENTING SYMPTOMS"

\begin{tabular}{|c|c|c|c|c|c|}
\hline \multirow[t]{3}{*}{ Independent variable } & \multicolumn{3}{|c|}{ Scores } & \multirow[t]{3}{*}{ Chi square value } & \multirow[t]{3}{*}{ P value } \\
\hline & \multirow[t]{2}{*}{ Parameters } & $\begin{array}{c}\text { No } \\
\text { Symptom }\end{array}$ & $\begin{array}{c}\text { Symptom } \\
\text { present }\end{array}$ & & \\
\hline & & No. (\%) & No. (\%) & & \\
\hline \multirow[t]{2}{*}{ Gender } & Female & $30(24.8)$ & $91(75.2)$ & \multirow[t]{2}{*}{0.44} & \multirow[t]{2}{*}{0.508} \\
\hline & Male & $34(28.6)$ & 85 (71.4) & & \\
\hline \multirow[t]{2}{*}{ Literacy } & Literate & $38(27.7)$ & $99(72.3)$ & \multirow[t]{2}{*}{0.19} & \multirow[t]{2}{*}{0.67} \\
\hline & Illiterate & $26(25.2)$ & $77(74.8)$ & & \\
\hline \multirow[t]{2}{*}{ Sleep } & Normal & $61(29.3)$ & $147(70.7)$ & \multirow[t]{2}{*}{5.65} & \multirow[t]{2}{*}{0.018} \\
\hline & Reduced & $3(9.4)$ & $29(90.6)$ & & \\
\hline \multirow[t]{2}{*}{ Appetite } & Normal & $64(28.8)$ & $158(71.2)$ & \multirow[t]{2}{*}{7.08} & \multirow[t]{2}{*}{0.008} \\
\hline & Reduced & $0(0)$ & $18(100)$ & & \\
\hline \multirow[t]{2}{*}{ Addictions } & No & $58(27.2)$ & $155(72.8)$ & \multirow[t]{2}{*}{0.31} & \multirow[t]{2}{*}{0.58} \\
\hline & Yes & $6(22.2)$ & $21(77.8)$ & & \\
\hline \multirow[t]{2}{*}{ Physical activity } & Yes & $33(63.5)$ & 19 (36.5) & \multirow[t]{2}{*}{45.96} & \multirow[t]{2}{*}{$<0.000$} \\
\hline & No & $31(16.5)$ & $157(83.5)$ & & \\
\hline \multirow[t]{2}{*}{ Nutritional requirement (Protein / Calorie) } & No & $55(27.1)$ & $148(72.9)$ & \multirow[t]{2}{*}{0.12} & \multirow[t]{2}{*}{0.73} \\
\hline & Deficient & $9(24.3)$ & $28(75.7)$ & & \\
\hline \multirow[t]{2}{*}{ Depression } & No & $62(28.6)$ & $155(71.4)$ & \multirow[t]{2}{*}{4.2} & \multirow[t]{2}{*}{0.04} \\
\hline & Yes & $2(87)$ & $21(91.3)$ & & \\
\hline
\end{tabular}

\begin{tabular}{|c|c|c|c|c|c|}
\hline \multirow[t]{3}{*}{ Independent variable } & \multicolumn{3}{|c|}{ Scores } & \multirow[t]{3}{*}{ Chi square value } & \multirow[t]{3}{*}{ P-Value } \\
\hline & \multirow[t]{2}{*}{ Parameters } & No morbidity & Morbidity present & & \\
\hline & & No. (\%) & No. (\%) & & \\
\hline \multirow[t]{2}{*}{ Gender } & Female & 14 (11.6) & $107(88.4)$ & \multirow[t]{2}{*}{0.66} & \multirow[t]{2}{*}{0.418} \\
\hline & Male & $18(15.1)$ & $101(84.9)$ & & \\
\hline \multirow[t]{2}{*}{ Literacy } & Literate & $19(13.9)$ & $118(86.1)$ & \multirow[t]{2}{*}{0.08} & \multirow[t]{2}{*}{0.78} \\
\hline & Illiterate & $13(12.6)$ & $90(87.4)$ & & \\
\hline \multirow[t]{2}{*}{ Sleep } & Normal & $32(15.4)$ & $176(84.6)$ & \multirow[t]{2}{*}{5.68} & \multirow[t]{2}{*}{0.017} \\
\hline & Reduced & $0(0)$ & $32(100)$ & & \\
\hline \multirow[t]{2}{*}{ Appetite } & Normal & $32(14.4)$ & $190(85.6)$ & \multirow[t]{2}{*}{2.99} & \multirow[t]{2}{*}{0.084} \\
\hline & Reduced & $0(0)$ & $18(100)$ & & \\
\hline \multirow[t]{2}{*}{ Addictions } & No & $32(13.33)$ & 181 (86.67) & \multirow[t]{2}{*}{4.68} & \multirow[t]{2}{*}{0.031} \\
\hline & Yes & $07(0)$ & $27(100)$ & & \\
\hline \multirow[t]{2}{*}{ Physical activity } & Yes & $18(34.6)$ & $34(65.4)$ & \multirow[t]{2}{*}{26.02} & \multirow[t]{2}{*}{$<0.001$} \\
\hline & No & $14(7.4)$ & $174(92.6)$ & & \\
\hline \multirow{2}{*}{$\begin{array}{l}\text { Nutritional requirement } \\
\text { (Protein / Calorie) }\end{array}$} & No & $31(15.3)$ & $172(84.7)$ & \multirow[t]{2}{*}{4.28} & \multirow[t]{2}{*}{0.039} \\
\hline & Deficient & $1(2.7)$ & $36(97.3)$ & & \\
\hline \multirow[t]{2}{*}{ Depression } & No & $32(14.7)$ & $185(85.3)$ & \multirow[t]{2}{*}{3.91} & \multirow[t]{2}{*}{0.48} \\
\hline & Yes & $0(0)$ & $23(100)$ & & \\
\hline
\end{tabular}


TABLE 6 ASSOCIATION OF DIFFERENT PARAMETERS WITH PRESENCE OR ABSENCE OF “MULTI SYSTEM INVOLVEMENT"

\begin{tabular}{|c|c|c|c|c|c|}
\hline \multirow[t]{3}{*}{ Independent variable } & \multicolumn{3}{|c|}{ Scores } & \multirow[t]{3}{*}{ Chi square value } & \multirow[t]{3}{*}{ P value } \\
\hline & \multirow[t]{2}{*}{ Parameters } & $\begin{array}{c}\text { No } \\
\text { multisystem } \\
\text { morbidity }\end{array}$ & $\begin{array}{c}\text { Multisystem } \\
\text { morbidity } \\
\text { present }\end{array}$ & & \\
\hline & & No. (\%) & No. (\%) & & \\
\hline \multirow[t]{2}{*}{ Gender } & Female & $74(61.2)$ & $47(38.8)$ & \multirow[t]{2}{*}{4.25} & \multirow[t]{2}{*}{0.039} \\
\hline & Male & 57 (47.9) & $62(52.1)$ & & \\
\hline \multirow[t]{2}{*}{ Literacy } & Literate & $85(62)$ & $52(38)$ & \multirow[t]{2}{*}{7.17} & \multirow[t]{2}{*}{0.007} \\
\hline & Illiterate & $46(44.7)$ & $57(55.3)$ & & \\
\hline \multirow[t]{2}{*}{ Sleep } & Normal & $121(58.2)$ & $87(41.8)$ & \multirow[t]{2}{*}{8.11} & \multirow[t]{2}{*}{0.004} \\
\hline & Reduced & $10(31.3)$ & $22(68.8)$ & & \\
\hline \multirow[t]{2}{*}{ Appetite } & Normal & $125(56.3)$ & $97(43.7)$ & \multirow[t]{2}{*}{3.56} & \multirow[t]{2}{*}{0.06} \\
\hline & Reduced & $6(33.3)$ & $12(66.7)$ & & \\
\hline \multirow[t]{2}{*}{ Addictions } & No & $126(59.2)$ & $87(40.8)$ & \multirow[t]{2}{*}{15.96} & \multirow[t]{2}{*}{$<0.001$} \\
\hline & Yes & $5(18.5)$ & $22(81.5)$ & & \\
\hline \multirow[t]{2}{*}{ Physical activity } & Yes & $33(63.5)$ & $19(36.5)$ & \multirow[t]{2}{*}{2.11} & \multirow[t]{2}{*}{0.146} \\
\hline & No & $98(52.1)$ & $90(47.9)$ & & \\
\hline \multirow[t]{2}{*}{ Nutritional requirement (Protein / Calorie) } & No & $116(57.1)$ & 87 (42.9) & \multirow[t]{2}{*}{3.48} & \multirow[t]{2}{*}{0.062} \\
\hline & Deficient & $15(40.5)$ & $22(59.5)$ & & \\
\hline
\end{tabular}

\section{Figures}

FIGURE 1 FREQUENCY DISTRIBUTION OF PRESENTING COMPLAINTS

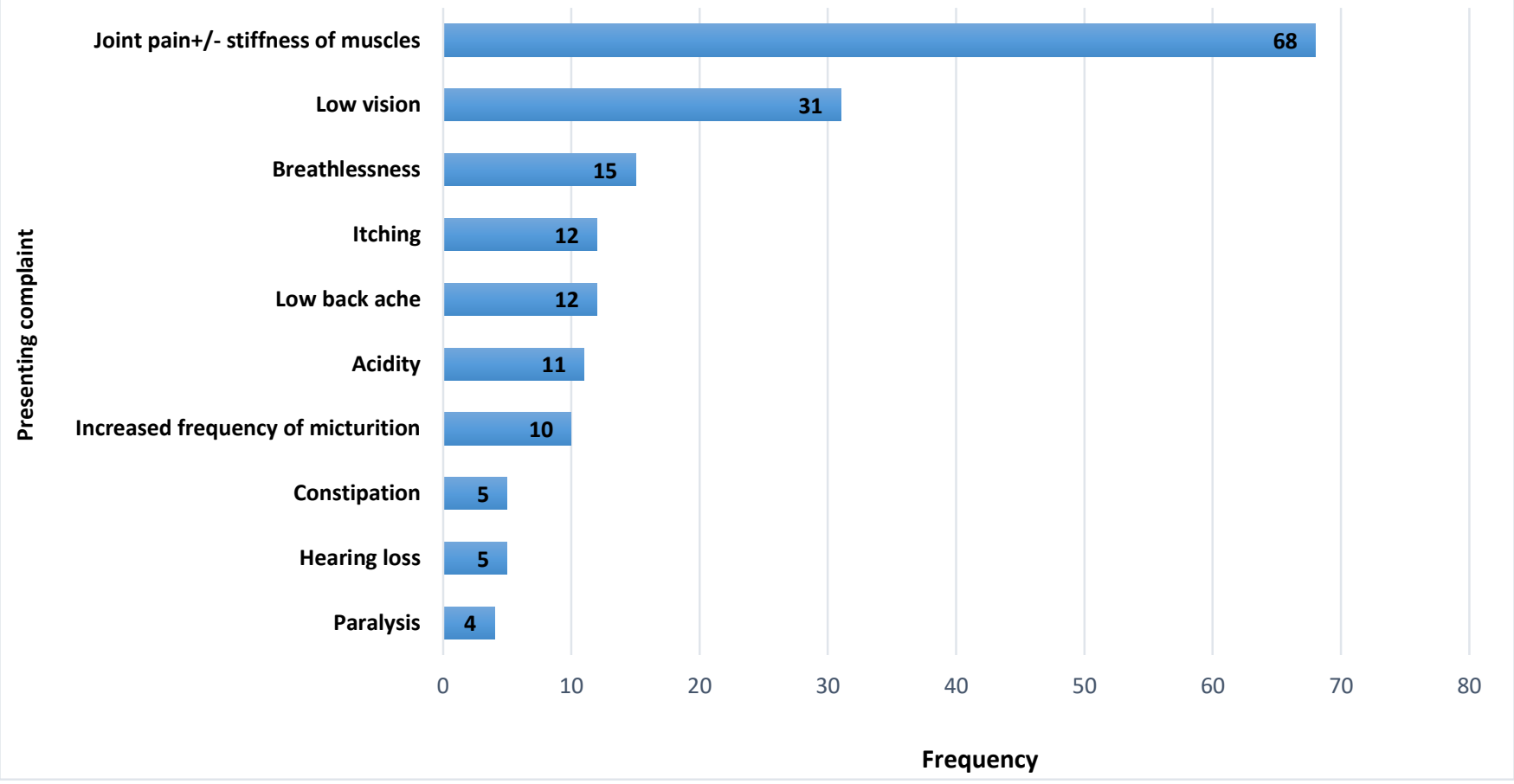

